\title{
Hepatocellular Carcinoma: Risk Factors, Diagnosis, Staging and Treatment in a Referral Centre
}

\author{
Raphael Raphe ${ }^{1}$, Willian J. Duca ${ }^{2}$, Paulo C. Arroyo Jr. ${ }^{2}$, Rita C. da Silva ${ }^{3}$, Renato F. da Silva ${ }^{2}$ \\ ${ }^{1}$ Postgrauduate Course, Faculty of Medicine of São Jose do Rio Preto, FAMERP, São Jose do Rio Preto, Brazil; ${ }^{2}$ Unit of Surgery and \\ Liver Transplant, Department of Surgery, Hospital de Base FUNFARME/FAMERP, São Jose do Rio Preto, Brazil; ${ }^{3}$ Unit of Surgery \\ and Liver Transplant, Department of Medicine, Hospital de Base FUNFARME/FAMERP, São Jose do Rio Preto, Brazil. \\ Email: raphael@raphe.com.br
}

Received December $21^{\text {st }}$, 2012; revised January $24^{\text {th }}, 2013$; accepted February $3^{\text {rd }}, 2013$

\begin{abstract}
Introduction: Hepatocellular carcinoma is the most common primary neoplasm of the liver and a significant cause of mortality in patients with cirrhosis. A retrospective cross-sectional study was performed to analyze epidemiological aspects related to risk factors, diagnosis, staging and first-line treatment in a closed population. Methods: The medical records of patients seen between November 1998 and May 2011 were revisited. Results: Of the 272 patients included in this study, 229 (84.2\%) were male and the average age was 57.1 years (standard deviation 10.9 years). The most common etiology was hepatitis C virus infection in 145 (55.1\%) patients, with this being the single cause in 88 (33.4\%) patients. The largest masses ranged from $6 \mathrm{~mm}$ to $260 \mathrm{~mm}$ in diameter with a mean of $61.4 \mathrm{~mm}$ (standard deviation 41.5 $\mathrm{mm})$. Only one mass was found in 145 (64.2\%) cases, two masses in $26(11.5 \%)$, three masses in 9 (4\%) and 46 patients (20.3\%) had multifocal disease. Early stage disease was diagnosed in 47 patients (22.0\%), advanced stage in 65 (30.4\%) and terminal stage in 32 (14.9\%). Hepatocellular carcinoma was found by chance in $11 \%$. Diagnosis was by means of imaging in 175 (68.1\%) cases. The level of alpha-fetoprotein was measured in 209 patients, with $29.2 \%$ having levels lower than $20 \mathrm{ng} / \mathrm{mL}$ and 34.9\% having levels above $400 \mathrm{ng} / \mathrm{mL}$. Specific treatment was administered in 236 patients (86.8\%) with hepatic chemoembolization in 127 (46.7\%) and liver transplantation in 72 (26.5\%); of these 33 (45.8\%) received hepatic chemoembolization as a bridge to transplantation. Thirty-four patients (12.5\%) received only supportive therapy. Conclusions: Patients are chiefly male and disease involvement generally occurs in the 5th decade of life. Cirrhosis was present in most patients and hepatitis C virus infection was the commonest etiologic agent. Only one imaging examination was required for diagnosis in most patients. The measurement of alpha-fetoprotein levels did not prove to be a good tool in the diagnosis of hepatocellular carcinoma. Intermediate, advanced and terminal stages predominated compared to early stages. Treatment was based on non-curative therapies.
\end{abstract}

Keywords: Hepatocellular Carcinoma; Epidemiology; Risk Factors; Liver Cancer; Hepatitis; Alcohol

\section{Introduction}

Hepatocellular carcinoma (HCC) is the most common liver cancer and its incidence is increasing significantly [1]; statistically in men it is the 5th most common cancer and the 2nd in cancer-related deaths and in women it is the 7th most common cancer and the 6th in cancer-related deaths $[2,3]$.

There is great geographical variability in HCC incidence rates related to etiological factors such as infections by hepatitis B (HBV) and hepatitis C viruses (HCV) and exposure to aflatoxin B1 [4].

Men are more affected by HCC than women with frequencies 4 to 8 times higher in men depending on the region. Factors such as the higher rates of cirrhosis in men, greater alcohol consumption, exposure to toxins (tobacco and aflatoxins) and the influence of male sex hormones explain, in part, this higher incidence [2,5].

The incidence of HCC increases with age, with the highest prevalence in individuals aged around 65 years old due to the large number of cirrhotic livers in this age group and the increased longevity; this disease is rare in under 40 years old [6-8].

Worldwide around $50 \%$ of cases of HCC, including virtually all cases in children, are related to chronic HBV infection. In endemic regions, such as Asia and Africa, where the transmission is from mother to child, about $90 \%$ of those infected will evolve with chronic disease when interactions with the human DNA frequently take place. HBV infection can cause HCC even in the absence of cirrhosis with treatment decreasing, but not eliminat- 
ing risk [9]. In HCV-infected individuals, the risk factors for HCC include advanced age, male gender, co-infection with HIV or HBV, obesity and diabetes, high iron overload and consumption of alcohol $[10,11]$. HCV-infected individuals have an estimated risk for cirrhosis of $10 \%$ to $30 \%$ per year and for HCC of $1 \%$ to $3 \%$ per year [12].

The most important risk factor for the development of HCC is cirrhosis, present in $80 \%$ to $90 \%$ of patients [13, 14]. The accumulated risk at five years for the development of HCC in cirrhotic patients ranges from 5\% to 30\% depending on the cause, region, ethnic group and stage of cirrhosis, with higher risk in uncontrolled cirrhotic patients [15].

There is little evidence of direct carcinogenic effects due to alcohol, however consumption may be the cause of HCC and alcohol in association with HBV and HCV has a synergistic effect in the evolution of the disease, with a two-fold increase in the risk for these patients [16].

It is estimated that there are 47 million Americans with metabolic syndrome [17], another risk factor for HCC [18]. Diabetes is also associated with HCC [19,20]. Nonalcoholic fatty liver disease (NAFLD), present in 90\% of all obese individuals and more than $70 \%$ of people with type 2 diabetes, is reported to be a possible risk factor for HCC, however the true risk remains unclear [21,22]. Abdominal ultrasound and the alpha-fetoprotein serum marker concentration are most commonly used to screen for HCC. Other serum markers, such as des-y-carboxy prothrombin, interleukin-18 and glypican-3 have also been studied $[23,24]$. Staging is used to determine the prognosis and to guide treatment. In most patients, the factors used to stage HCC are the underlying disease, however, the key prognostic factors have not been well defined yet and the prognostic factors may vary in the course of the disease [25].

The stage of the tumor, liver function, the patient's clinical condition and the effectiveness of treatment are conditions that determine the prognosis in HCC $[26,27]$. Several staging systems have been developed for HCC and they have been validated at several levels however the system of the Barcelona Liver Cancer Clinic (BLCC) is the only one that aggregates all information and correlates it with prognosis [28].

Surgical resection is indicated in patients who have a single lesion without cirrhosis or those who have cirrhosis but a good hepatic functional reserve with normal levels of bilirubin and the absence of portal hypertension. Pre-or post-resection adjuvant therapies are not recommended [23]. The risk of relapse after resection is high due to chronic liver disease.

Liver transplantation is an effective option in HCC patients that fall in the criteria of Milan (a mass of less than or equal to $50 \mathrm{~mm}$ or three nodules smaller than or equal to $30 \mathrm{~mm}$ ) [29]. Inter vivos transplantation can be offered if the length of the waiting list is longer than the time estimated to exclude the patient due to tumor progression resulting in ineligibility according to the criteria of Milan [23].

The best alternatives for patients with early tumors that are not eligible for surgical resection or transplantation include radiofrequency and alcohol injection ablation. Radiofrequency ablation has provided better results than alcohol injection [30]. Results of two randomized trials evaluating resection and radiofrequency ablation showed similar relapse and survival rates with a lower rate of complications and hospitalizations with ablation [31,32]. Hepatic chemoembolization is considered the first line treatment for non-surgical patients with multifocal disease or large HCC who do not have vascular invasion or extrahepatic disease. The use of sorafenib ${ }^{\circledR}$ is recommended as first line treatment for patients who are not candidates for surgery, transplantation, ablation or hepatic chemoembolization, but who still have good liver function [23].

Radioembolization with yttrium-90 has proved to be safe and effective in patients with HCC, including those with portal vein thrombosis. However, there are no publications showing increased survival or reporting on comparisons with other methods. Systemic or selective intraarterial chemotherapy is not recommended and cannot be used in standard care [23].

Given the increasing incidence of HCC observed in different world regions, driven by rising risk factors, as well as the diagnosis and different treatment modalities based on the stage of the disease, this manuscript sought to examine these characteristics retrospectively, in a study descriptive, cross-sectional in a teaching hospital that aimed to evaluate clinical and epidemiological aspects of HCC patients comparing the results with those indicated in literature.

\section{Patients and Methods}

A retrospective, descriptive, cross-sectional study was performed based on data collected from the medical records of individuals diagnosed with HCC in the period from November 1998 to May 2011.

Clinical and epidemiological data were collected including gender, age at diagnosis, presence of cirrhosis, liver disease etiology and the Child-Pugh (CP) score. Moreover, data were collected about the HCC and treatments carried out, including characteristics of the tumors (number, diameter of masses and presence of vascular invasion), the alpha-fetoprotein level and the type of therapy used. Patients were classified according to the etiology of liver disease as: 1) HCV, 2) HBV, 3) alcoholic liver disease (ALD); 4) NAFLD; 5) hemochromatosis $(\mathrm{HH})$; 6) associations and 7) others including autoimmune hepatitis, primary biliary cirrhosis and cryptogenic 
causes.

Data on the CP classification were included [33]. Patients were also subdivided into five stages according to the BLCC [28] as (0) very early stage-a mass of less than $20 \mathrm{~mm}$ in diameter, CP class A; (A) early stage-a mass of less than $50 \mathrm{~mm}$ in diameter or three masses with diameters of less than $30 \mathrm{~mm}$, CP class A or B with absence of vascular invasion; (B) intermediary stage-a mass greater than $50 \mathrm{~mm}$ in diameter or more than three masses, CP class A or B with absence of vascular invasion; (C) advanced stage-any mass, CP class A or B and the presence of vascular invasion and/or extrahepatic metastasis and (D) terminal stage-any mass and CP class $\mathrm{C}$. The patient's general health state evaluated using the Eastern Cooperative Oncology Group Performance Status Scale (ECOG-PST) [34] could not be inferred due to the lack of information in patients' records.

The initial therapy used to treat HCC included 1) resection, 2) liver transplant, 3) ablative therapies (radiofrequency and alcohol injection), 4) transarterial embolization and chemoembolization, 5) use of sorafenib ${ }^{\circledR}$ and 6) supportive therapy.

The study was approved by the Research Ethics Committee of the institution. Statistical analysis was performed using the Minitab ${ }^{\circledR} 15$ software and the level of significance was set for a p-value $<0.05$.

\section{Results}

This study included 272 HCC patients; 229 men (84.2\%) and 43 women (15.8\%) (ratio: 5.3:1). The mean age was 57.1 years (standard deviation-SD: 10.9 years), ranging from 22 to 88 years. More than half the patients (51.7\%) were 57 years old or less. Most patients (91.5\%) were Caucasians. Cirrhosis was present in 267 (98.2\%) of cases; 102 (38.2\%) cases were in CP class A; 104 (38.9\%) in CP class B and 51 (19.1\%) were in CP class C. No records were available in respect to CP class for ten (3.8\%) patients.

Table 1 shows the etiology of the chronic liver disease of the 272 HCC patients. The main etiological groups were: HCV alone in 88 (33.4\%) patients and associated to alcohol in 30 (11.4\%); HBV alone in 46 (15.5) patients and associated to alcohol in 8 (3.0\%); ALD in 38 (14.4\%) patients and the association of HCV and HBV in 12 (4.6\%) patients. Other causes, including autoimmune hepatitis, primary biliary cirrhosis and unknown causes were reported for 18 (6.8\%) patients.

The diagnosis of HCC was made by ultrasound imaging in 175 (68.1) patients. Thirteen (5.1\%) patients performed two exams. In 39 (15.1\%) patients, a biopsy was performed and $30(11.7 \%)$ patients were diagnosed by chance based on lesions identified at the time of transplantation. For 15 patients, details of the diagnosis were unavailable. Figure 1 shows the distribution of annual incidence rates for cases of HCC.

Of the 209 patients for whom alpha-fetoprotein was measured, 29.2\% ( $\mathrm{n}=61$ ) had levels of less than 20 $\mathrm{ng} / \mathrm{mL}$; 45.9\% ( $\mathrm{n}=96$ ) had levels less than $100 \mathrm{ng} / \mathrm{mL}$ and 34.9\% ( $=73$ ) had levels above $400 \mathrm{ng} / \mathrm{mL}$. Additionally, $67.8 \%(19 / 28)$ of the cases that presented masses with diameters greater than or equal to $100 \mathrm{~mm}$ presented alpha-fetoprotein levels above $400 \mathrm{ng} / \mathrm{mL}$.

Table 2 presents the characteristics of the patients' tumors. Although the presence of at least one mass was identified in 226 patients, the diameter was not measured

Table 1. Clinical and epidemiological data of patients $(n=$ 272).

\begin{tabular}{ccc}
\hline Variable & \multicolumn{2}{l}{ Result } \\
\hline Etiology ${ }^{*}$ & 88 & $33.4 \%$ \\
VHC & 46 & $17.5 \%$ \\
VHB & 38 & $14.4 \%$ \\
ALD & 30 & $11.4 \%$ \\
VHC + ALD & 12 & $4.6 \%$ \\
VHB + VHC + ALD & 12 & $4.6 \%$ \\
VHC + VHB & 8 & $3.0 \%$ \\
VHB + ALD & 5 & $1.9 \%$ \\
NAFLD & 2 & $0.8 \%$ \\
VHB + others & 1 & $0.4 \%$ \\
HEMOC & 1 & $0.4 \%$ \\
VHC + others & 1 & $0.4 \%$ \\
VHB + VHC + others & 1 & $0.4 \%$ \\
VHB + VHC + ALD + HEMOC & 18 & $6.8 \%$ \\
others & & \\
\hline
\end{tabular}

*9 patients did not have available records $(n=263)$. VHC = hepatitis $\mathrm{C}$ virus; VHB = hepatitis B virus; ALD = alcoholic liver disease; NAFLD = nonalcoholic fatty liver disease; HEMOC = hemochromatosis

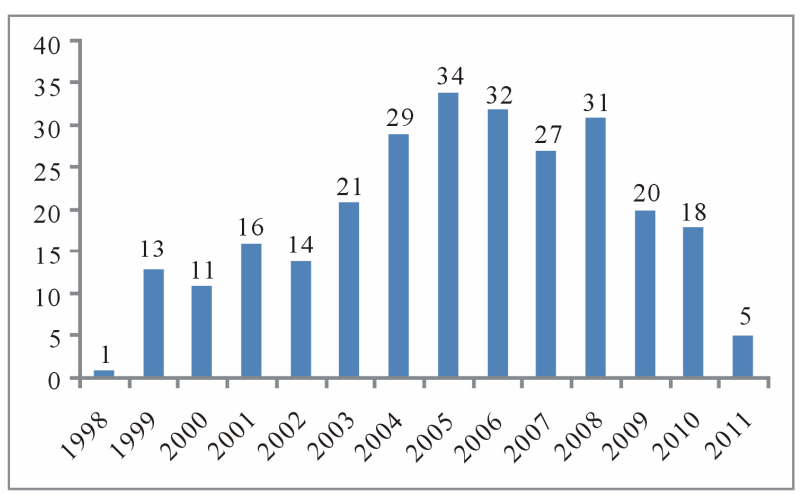

Figure 1. Incidence of hepatocellular carcinoma in the study period (November1998 to May 2011). 
or recorded in patients' records in every case. However, available data on the largest masses of 220 patients when more than one was identified, showed that the largest diameter ranged from $6 \mathrm{~mm}$ to $260 \mathrm{~mm}$ with a mean of $61.4 \mathrm{~mm}$ and SD of $41.5 \mathrm{~mm}$.

Of all the patients, the number of masses was identified by imaging in 226 patients; 145 (64.2\%) had only one mass, 26 (11.5\%) had 2 masses, 9 (4.0\%) patients had three masses and 46 (20.3\%) patients were characterized as multifocal. There were no details in the medical records on this variable for 16 patients and 30 (11.0\%) patients were diagnosed by chance after liver transplantation.

Of the 220 patients who had details on the diameter of the largest mass, $10(4.56 \%)$ patients had masses of less than or equal to $20 \mathrm{~mm}$ in diameter, 112 (50.9\%) had masses with diameters greater than $20 \mathrm{~mm}$ and less than or equal to $50 \mathrm{~mm}$ and in 98 (44.54\%) the diameter was greater than $50 \mathrm{~mm}$. Moreover, 87 (39.5\%) of 220 patients met the criteria of Milan.

A total of 214 patients were staged using available data taking into account the CP score, number of masses, diameter and presence or absence of macrovascular invasion. Of this total, 70 (32.7\%) were in early stage, 47 (22.0\%) in intermediate stage, 65 (30.4\%) in advanced stage and $32(14.9 \%)$ in terminal stage of the disease. No patient was classified in the very early stage. For 28 pa-

Table 2. Characteristics of tumors and BCLC staging.

\begin{tabular}{ccc}
\hline Variable & \multicolumn{2}{c}{ Result } \\
\hline Diameter of mass (mm) & \multicolumn{2}{c}{61.4} \\
Mean & \multicolumn{2}{c}{41.5} \\
Standard deviation & \multicolumn{2}{c}{$6-260$} \\
Range & \multicolumn{2}{c}{} \\
Number of masses ${ }^{*}$ & 145 & $(64.2 \%)$ \\
One & 26 & $(11.5 \%)$ \\
Two & 9 & $(4.0 \%)$ \\
Three & 46 & $(20.3 \%)$ \\
Multifocal & & \\
HCC stage (BCLC) & \\
O-Very early & 0 & $(0 \%)$ \\
A-Early & 70 & $(32.71 \%)$ \\
B-Intermediary & 47 & $(21.96 \%)$ \\
C-Advanced & 65 & $(30.37 \%)$ \\
D—-Terminal & 32 & $(14.95 \%)$ \\
\hline
\end{tabular}

*16 patients had no available records and 30 diagnoses were by chance; ${ }^{+} 28$ patients had incomplete data for staging. HCC = carcinoma hepatocellular; BCLC = Barcelona Liver Cancer Clinic. tients staging data were incomplete and 30 patients were diagnosed by chance.

A total of 236 patients (86.8\%) were managed using specific treatment for HCC. This included resection of the tumor in $29(10.7 \%)$ cases, liver transplantation in 72 (26.5\%) with 33 (45.8\%) patients receiving hepatic chemoembolization as a "bridge" to transplantation, radiofrequency or alcohol injection ablation in 5 (1.8\%) patients, hepatic chemoembolization in 127 (46.7\%) and the use of Sorafenib ${ }^{\circledR}$ in $3(1.1 \%)$ cases. Thirty-four patients (12.5\%) received only supportive therapy. Two $(0.7 \%)$ patients had no record of their treatment (Table 3).

\section{Discussion}

Hepatocellular carcinoma is considered one of the most important malignant diseases today as it is the leading cause of death and the most common complication in patients with cirrhosis. In recent years there has been an increase in its incidence and it is estimated that the number of cases continues to grow [5]. However, there are few national publications that report on this disease; the current study involved a cohort of 272 HCC patients treated at a single Center.

Carrilho et al. [35], in a multicenter survey of 1405 Brazilian patients with HCC over a six-year period, found that $78 \%$ of their patients were male. Two studies in public hospitals involving 210 and 36 HCC patients reported higher prevalences of men (76.6\% and 83.3\%) [36,37]. Gonçalves et al. [38] in another Brazilian multicenter survey over a three-year study period evaluated 287 cases and calculated a ratio of 3.4 men to every woman. In a publication involving Latin America countries [39], a multicenter survey over 18 months involving 240 HCC patients found that 174 (72.5\%) were male. In North America, a 2008 publication reported incidences in men and women of 6.8 and 2.2 per 100,000 people, respectively [1]. Varela et al. [40] studied 705 patients in 62 centers in Spain and found $78 \%$ were men with a ratio of 3.51 men for every woman. In several European countries there is a predominance of men with a mean ratio of $6.7 / 2.3$ men/women. The predominance of men was also

Table 3. Treatment administered for HCC.

\begin{tabular}{ccc}
\hline Treatment & n (236) & \% \\
\hline Surgical resection & 29 & 10.7 \\
Liver transplantation & 72 & 26.5 \\
Ablative therapies & 5 & 1.8 \\
Chemoembolization & 127 & 46.7 \\
Sorafenib ${ }^{\circledR}$ & 3 & 1.1 \\
Support therapies & 34 & 12.5 \\
\hline
\end{tabular}


noted in Eastern countries, for example in China with 23 men to 9.8 woman and in Japan with 20.5 men to 7.8 women. Globally, the mean is reported to be 16 men for every six women [41]. Thus this study corroborates published data with the predominance of men (84.2\%) gaving a ratio of 5.3 men for every woman. The mean age observed in this study was 57.1 years. Brazilian publications report mean ages of 54.6 years (range: 35 to 80 ) [42], 55.9 years (SD \pm 15 ) [38], 62.8 years [36] and 59 years (range: 1 to 92) [35]. In Latin America, the mean age published in one study was 64 years (range: 19 to 92) [39]. A multicenter study in Spain reported a mean age of 65.6 years (range: 22 to 93 ) [40]. Over the years, the mean age has increased which may be attributed to better care of cirrhotic patients. In Western countries, except Japan and Africa, the mean age of 40 is attributed to the great epidemic of HBV infection that affects babies and children [43]. The literature reports a great predominance of cirrhosis as a risk factor in HCC cases. In Brazil, a national survey [38] found cirrhosis in $71.2 \%$ of cases and more recently, Carrilho et al. [35] stated that $98 \%$ of the cases were associated with HCC. Studies in Latin American [39] and Spain [40] reported occurrences of cirrhosis associated with HCC in $89 \%$ and $85.4 \%$, respectively. Sherman [44] reported that the annual risk of cirrhotic patients developing HCC is from 1 to $6 \%$. In the current study, the presence of cirrhosis at diagnosis of HCC was $98.2 \%$, thus corroborating the high rates presented in the literature (Table 4).

Regarding the etiology of liver disease, a study of the Brazilian population published in 1997 reported that HBV infection was present in $39.4 \%$ of HCC cases, followed by HCV infection in $37.4 \%$ and ALD in $26.9 \%$ [38]. Another multicenter study in 2010 showed that HCV infection was present in $54 \%$ of patients $(39 \%$ in isolation), ALD in $33 \%$ (14\% in isolation) and $\mathrm{HBV}$ infection in $15 \%$ (12\% in isolation) [39]. A survey of 210 patients from a single center demonstrated that the most prevalent causes were HCV infection in $42 \%$, followed by ALD in 39\% (26.6\% in isolation) and HBV infection in $16.6 \%$ [36]. A comparison of these results with a survey published by this institution at the beginning of the last decade shows that there was a change in the main etiological factors; at that time HBV was the leading cause followed by HCV and in the current study HCV is followed by ALD. There are regional variations in the etiology of HCC around the world. A Latin American study of 240 patients revealed that the primary etiology of chronic liver disease was HCV in $30.8 \%$ of cases. HCV infection associated with ALD was reported in $5.8 \%$. ALD was involved in isolation in $20.4 \%$ of cases followed by cryptogenic cirrhosis in $14.6 \%$ [39]. A study based on the population of the USA, conducted in several centers, showed that HCV infection was identified in $46.7 \%$ of the cases followed HBV infection in $15.4 \%$, an association of HCV and HBV infections in $4.7 \%$ and 33.1\% had other causes [45]. The most frequent etiology identified in a Spanish multicenter study of 705 cases was HCV infection in $42.3 \%$, followed by ALD in 30.2\% and the association of HCV infection with ALD in 9.2\% of the cases [40]. According to Bosch et al. [46], the incidence of HCC varies in different countries depending on the prevalence of the major causes, that is, chronic liver disease caused by chronic viral infection or by other causes. The estimated risk assigned to HCC in Western countries is $60 \%$ for HCV infection and in Eastern countries it is $60 \%$ for HBV infection. Chronic HBV infection is the most common risk factor in the world for HCC; it is present in $52.3 \%$ of all HCC cases. HCV infection is the second most common cause ( $20 \%$ of all HCC cases). The current study showed that HCV infection was the most prevalent involving $55.1 \%$ of HCC cases (33.4\% in isolation). The second most prevalent etiology was ALD in $33.8 \%$ (14.4\% in isolation). HBV infection was present in $31.2 \%$ of HCC cases (17.5\% in isolation). Statistical analysis in this study shows that there is a predominance of men with ALD and women with HCV infection as the cause of HCC. Recent studies have shown an increased incidence of HCC caused by metabolic syndrome, a global endemic condition [18]. In the current study, metabolic syndrome was observed in $1.9 \%$ of the cases. Hence, in this investigation the study population resembles those of Western countries. On comparing these results with those of surveys published in past decades,

Table 4. Comparison of clinical characteristics between studies.

\begin{tabular}{ccccccccc}
\hline \multicolumn{10}{c}{ Characteristics clinical } \\
\hline & Raphe 2012 & $\begin{array}{c}\text { Carrilho 2010 } \\
{[35]}\end{array}$ & $\begin{array}{c}\text { Fassio 2010 } \\
{[32]}\end{array}$ & $\begin{array}{c}\text { Varela 2010 } \\
{[30]}\end{array}$ & $\begin{array}{c}\text { Alves 2009 } \\
{[36]}\end{array}$ & $\begin{array}{c}\text { Ferreira 2009 } \\
{[32]}\end{array}$ & $\begin{array}{c}\text { Silva 2001 } \\
{[42]}\end{array}$ & $\begin{array}{c}\text { Gonçalves } \\
1997[38]\end{array}$ \\
\hline N & 272 & 1405 & 240 & 705 & 210 & 36 & 33 & 291 \\
Mean ages (SD) & $57.1(10.9)$ & $59(11)$ & 64 & 65,6 & 62.8 & -- & 54.6 & $55.9(15)$ \\
Sex (M/F) & $5.3 / 1$ & $3.59 / 1$ & $2.63 / 1$ & $3.51 / 1$ & $3.2 / 1$ & $5 / 1$ & $5.6 / 1$ & $3.4 / 1$ \\
Cirrosis (\%) & 98.2 & 98 & 85.4 & 88.9 & --- & -- & 87.9 & 71.3 \\
\hline
\end{tabular}


metabolic syndrome was not the main etiologic cause of HCC. The present study corroborated results of several other recent publications [35,39] that showed a direct cause-effect relationship (Table 5).

In a national study published in 1997 [38], 91\% of 287 patients were diagnosed by histology. In the study of Carrilho et al. [35], of 1405 HCC cases, the majority (63\%) were diagnosed by imaging and only 15 were submitted to anatomopathological studies. Varela et al. [40], reported that, of 705 HCC cases, $71.7 \%$ of patients were diagnosed by imaging, $19.6 \%$ by biopsy and only $8.7 \%$ by physical examination, the measurement of alpha-fetoprotein levels and ultrasonography. These results are based on the recently updated guidelines of the AASLD [23] that recommend that 4-phase computed tomography or dynamic magnetic resonance imaging should be performed when a mass bigger than $10 \mathrm{~mm}$ is identified in a cirrhotic patient during screening by ultrasonography. The results of arterial hypervascularization and washout in the venous or late phases should be interpreted as HCC. For masses smaller than $10 \mathrm{~mm}$, a liver biopsy is needed to confirm diagnosis. In the current study, the diagnosis was mostly made by imaging examinations with $68.1 \%$ (175/257) requiring one examination and 5.1\% (13/257) requiring two imaging examinations. Histological diagnosis was used in $15.1 \%$ (39/257) of dubious cases. A significant number of patients $(11 \%)$ were diagnosed by chance after an anatomopathological examination of the liver submitted to transplantation. According to studies by Raphe et al. [47], an analysis of these cases concludes that most diagnoses of HCC are early with extensive survival (Table 6).

On evaluating the characteristics of tumors in a Spanish multicenter study, of 705 HCC cases, $44.7 \%$ were not within the criteria of Milan. It was found that in this study, $60.5 \%(133 / 220)$ of patients fitted the criteria of Milan, i.e. masses were less than or equal to $50 \mathrm{~mm}$ in diameter or three masses smaller than $30 \mathrm{~mm}$ in diameter [29]. In the Latin American study [39] of 240 cases, $63.3 \%$ had single masses and $12.5 \%, 6.7 \%$ and $13.3 \%$ had two, three and more masses, respectively. The pattern of masses was not described in $4.2 \%$ of the cases. In the current study, $64.2 \%$ had single masses, $11.5 \%$ had two masses and 4\% had three masses. Multifocal disease was diagnosed in $20 \%$ of the sample. On comparing the two studies, a similarity was seen in respect to the number of masses (Table 7).

In respect to HCC staging in a multicenter study in Spain [40], $49.8 \%$ of 705 cases were in the early stage (A), $19.8 \%$ in intermediate stage (B), $18.8 \%$ in advanced stage (C) and $11.6 \%$ in terminal stage (D) according to the BLCC classification. In a study in Latin America [18], $55.8 \%$ of the 240 cases were in stage A, $28.8 \%$ in stage B, $10.1 \%$ in stage $C$ and $5.3 \%$ in stage $D$. According to the BLCC classification, $32.7 \%$ cases of the current study were in stage A, 22\% cases in stage B, 30.4\% in stage C and $14.9 \%$ in stage $\mathrm{D}$; hence there was a high prevalence of the more advanced stages of the disease. This means that surveillance should be intensified so that HCC is diagnosed in earlier stages. On comparing data from patients in and out of monitoring programs in European [40] and Latin American [39] studies, the percentages of cases diagnosed in early stages are higher (Table 8).

With regard to treatment of HCC patients, Varela et al. [40] reported that $26.1 \%$ received symptomatic therapy (support), 25.6\% ablative therapies, 24.3\% hepatic chemoembolization and 9.4\% surgical resection. A study in Latin America [39] reported that 31.7\% did not receive

Table 5. Comparison of etiological factors between studies.

\begin{tabular}{|c|c|c|c|c|c|c|c|c|}
\hline \multicolumn{9}{|c|}{ Etiological factors (\%) } \\
\hline & Raphe 2012 & $\begin{array}{l}\text { Carrilho } \\
2010 \text { [35] }\end{array}$ & $\begin{array}{c}\text { Fassio } \\
2010 \text { [39] }\end{array}$ & $\begin{array}{c}\text { Varela } \\
2010[40]\end{array}$ & $\begin{array}{c}\text { Alves } \\
2009[36]\end{array}$ & $\begin{array}{c}\text { Ferreira } \\
2009 \text { [37] }\end{array}$ & $\begin{array}{c}\text { Silva } 2001 \\
\text { [42] }\end{array}$ & $\begin{array}{c}\text { Gonçalves } \\
1997 \text { [38] }\end{array}$ \\
\hline $\mathrm{HCV}$ & 33.4 & 39 & 30.8 & 42.3 & 42.5 & 60 & 38.7 & 26.9 \\
\hline ALD & 14.4 & 14 & 20.4 & 30.2 & 26.6 & --- & 44.8 & 37.4 \\
\hline $\mathrm{HBV}$ & 17.5 & 12 & 10.8 & 5.2 & 16.6 & --- & 40.6 & 39.4 \\
\hline NASH & 1.9 & 3 & 4.6 & 2.4 & --- & --- & --- & --- \\
\hline $\mathrm{HCV}+\mathrm{ALD}$ & 11.4 & 15 & 5.8 & 9.2 & --- & --- & 9.67 & 12.1 \\
\hline $\mathrm{HBV}+\mathrm{ALD}$ & 3.0 & 4 & 1.7 & --- & --- & --- & 12.9 & 8.3 \\
\hline $\mathrm{HCV}+\mathrm{HBV}$ & 4.6 & 2 & 0.8 & --- & --- & --- & --- & 3.8 \\
\hline $\mathrm{HCV}+\mathrm{HBV}+\mathrm{ALD}$ & 4.6 & -- & 0.4 & --- & --- & --- & 3.25 & 3.0 \\
\hline $\mathrm{HH}$ & 0.4 & 1 & 1.7 & 1.4 & --- & --- & --- & --- \\
\hline Othres & 8.8 & 10 & 22.9 & 9.2 & --- & --- & 9.67 & --- \\
\hline
\end{tabular}


Table 6. Comparison of methods diagnostics between studies.

\begin{tabular}{cccc}
\hline \multicolumn{4}{c}{ Method diagnostic (\%) } \\
\hline & Raphe 2012 & $\begin{array}{c}\text { Carrilho } \\
2010[35]\end{array}$ & $\begin{array}{c}\text { Varela } \\
2010[40]\end{array}$ \\
\hline 1 Imaging examination & 68.1 & 65.8 & 80.4 \\
2 Imaging examination & 5.1 & 18.1 & \\
$\begin{array}{c}\text { Anatomopathological } \\
\text { examination }\end{array}$ & 15.1 & 14.4 & 19.6 \\
Incidental & 11.7 & 1.7 & --- \\
\hline
\end{tabular}

Table 7. Comparison of characteristics of tumors between studies.

\begin{tabular}{cccc}
\hline \multicolumn{4}{c}{ Characteristics of tumors } \\
\hline & $\begin{array}{c}\text { Raphe } \\
2012\end{array}$ & $\begin{array}{c}\text { Varela } \\
2010[40]\end{array}$ & $\begin{array}{c}\text { Fassio } \\
2010[39]\end{array}$ \\
\hline single masse (\%) & 64.2 & 58.5 & 63.3 \\
two masses (\%) & 11.5 & --- & 12.5 \\
three masses (\%) & 4.0 & 9.4 & 6.7 \\
$>$ three masses (\%) & 20.3 & 32.1 & 13.3 \\
Criteria of Milan (\%) & 39.5 & 55.3 & --- \\
\hline
\end{tabular}

Table 8. Comparison between studies of staging.

\begin{tabular}{cccc}
\hline \multicolumn{4}{c}{ Estaging (\%) } \\
\hline & $\begin{array}{c}\text { Raphe } \\
2012\end{array}$ & $\begin{array}{c}\text { Varela } \\
2010[40]\end{array}$ & $\begin{array}{c}\text { Fassio } \\
2010 \text { [39] }\end{array}$ \\
\hline Very early stage (O) & 0 & 7.7 & --- \\
Early stage (A) & 32.71 & 42.1 & 55.8 \\
Intermediate stage (B) & 21.96 & 19.8 & 28.7 \\
Advanced stage (C) & 30.37 & 18.8 & 10.2 \\
Terminal stage (D) & 14.95 & 11.6 & 5.3 \\
\hline
\end{tabular}

specific treatment, $8.7 \%$ were submitted to surgical resection, $8.7 \%$ were transplanted, $17.5 \%$ received ablative therapies, $36.3 \%$ received hepatic chemoembolization and 2 received sorafenib ${ }^{\circledR}$. In a multicenter survey in Brazil by Caswell et al. [35], the most common treatment was chemoembolization in $36 \%$ of cases, followed by ablative therapy in $13 \%$, resection surgery in $7 \%$ and Sorafenib $^{\circledR}$ in $1 \%$. Liver transplantation was performed in $19 \%$ of cases, but it was performed as the initial treatment in only $4 \%$ of cases. In the current study, resection was performed in $10.7 \%$ of the cases, liver transplantation in $26.5 \%$ with approximately half of these cases (45.8\%) being submitted to chemoembolization before the surgery, ablative therapies in $1.8 \%$, chemoemboliza- tion in $46.7 \%$ as the only therapy, sorafenib ${ }^{\circledR}$ in $1.1 \%$ and $12.5 \%$ did not receive specific therapy for the tumor, that is, only clinical support therapy. In this study, both resection surgery and liver transplantation were similar to studies of Latin America [39] and Europe [40] (Table 9).

The treatment of HCC depends on the staging of the tumor, thus it is observed that more non-curative treatments are employed than curative treatments in this referral center compared to the Spanish study [40] where most patients received curative therapies. This consequently has a significant impact on the survival of patients.

Currently there are several serological markers available to monitor HCC. The most studied, and the one that was until recently was the only tool available, is alphafetoprotein. Its use in HCC monitoring programs is discouraged in new guidelines as, in many cases, levels are low in early tumors and it is well known that transitional elevations can occur in cirrhotic patients without tumors [24].

According to the studies of Trevisani et al. [48], Marrero et al. [49] and Lok et al. [50] who compared the accuracy of alpha-fetoprotein as a biomarker in the early detection of HCC with cut-off values between 10 and 20 $\mathrm{ng} / \mathrm{dL}$, the diagnostic sensitivity is about $60 \%$. In the current study, $29.2 \%$ of the cases presented normal alphafetoprotein levels, that is, less than $20 \mathrm{ng} / \mathrm{dL}$. Values above $200 \mathrm{ng} / \mathrm{dL}$ were observed in $46 \%$ of the cases. In respect to the size of the tumor, it was observed that tumors smaller than $30 \mathrm{~mm}$ have normal levels of alpha-fetoprotein and in tumors larger than $50 \mathrm{~mm}$, the level was greater than $200 \mathrm{ng} / \mathrm{dL}$ in $67.4 \%$ of the cases.

In conclusion, there is a predominance of males (84.2\%) and individuals are most affected in their $50 \mathrm{~s}$. Cirrhosis was present in the majority (98.2\%) of patients studied. HCV infection was the most common etiological agent found (33.4\%) in HCC patients. Most patients (68.1\%) only required one imaging examination to diagnose the disease. Measurement of alpha-fetoprotein levels did not prove to be a good diagnostic tool, because in $29.2 \%$ of cases it was normal $(20 \mathrm{ng} / \mathrm{dL})$ and in only $34.9 \%$ its

Table 9. Comparison of initial treatment between studies.

\begin{tabular}{ccccc}
\hline \multicolumn{5}{c}{ Initial treatment (\%) } \\
\hline & $\begin{array}{c}\text { Raphe } \\
2012\end{array}$ & $\begin{array}{c}\text { Varela } \\
2010 \text { [40] }\end{array}$ & $\begin{array}{c}\text { Fassio } \\
2010 \text { [39] }\end{array}$ & $\begin{array}{c}\text { Carrilho } \\
2010 \text { [35] }\end{array}$ \\
\hline Surgical resection & 11 & 9.4 & 8.7 & 7 \\
Liver transplantation & 17 & --- & 8.7 & 4 \\
Ablative therapies & 2 & 25.6 & 17.5 & 13 \\
Chemoembolization & 57 & 24.3 & 36.2 & 36 \\
Sorafenib & 1 & 12.4 & 2.0 & 1 \\
Support & 12 & 26.1 & 26.9 & 37 \\
\hline
\end{tabular}


value was equal to or greater than $400 \mathrm{ng} / \mathrm{dL}$. According to the BLCC classification there was a predominance of patients in the intermediate (21.96\%), advanced (30.37\%) and terminal stages (14.95\%) compared to the early stage (32.71\%); this study did not find any patients in the very early stage. Most of the treatment was based on non-curative therapies.

\section{REFERENCES}

[1] J. F. Perz, G. L. Armstrong, L. A. Farrington, W. J. Hutin and B. F. Bell, "The Contributions of Hepatitis B Virus and Hepatitis C Infectious to Cirrhosis and Primary Liver Cancer Worldwide,” Journal of Hepatology, Vol. 45, No. 4, 2006, pp. 529-538. doi:10.1016/j.jhep.2006.05.013

[2] F. B. Jemal, M. M. Center, J. Ferlay, E. Ward and D. Forman, "Global Cancer Statistics," CA Cancer Journal of Clinical, Vol. 61, No. 2, 2011, pp. 69-90. doi:10.3322/caac.20107

[3] S. F. Altekruse, K. A. McGlynn and M. E. Reichman, "Hepatocellular Carcinoma Incidence, Mortality, and Survival Trends in the United States from 1975 to 2005," Journal of Clinical Oncololy, Vol. 27, No. 9, 2009, pp. 1485-1491. doi:10.1200/JCO.2008.20.7753

[4] World Health Organization, International Agency for Research on Cancer, GLOBOCAN, 2008. http://globocan.iarc.fr

[5] T. Y. M. Leong and A. S. Y. Leong, "Epidemiology and Carcinogenesis of Hepatocellular Carcinoma," HPB (Oxford), Vol. 7, No. 1, 2007, pp. 5-15.

[6] H. B. El-Serag, "Epidemiology of Hepatocellular Carcinoma in USA," Hepatology Research, Vol. 37, No. S2, 2007, pp. S88-S94. doi:10.1111/j.1872-034X.2007.00168.x

[7] S. Parikh and D. Hyman, "Hepatocellular Cancer: A Guide for the Internist," American Journal of Medicine, Vol. 120, No. 3, 2007, pp. 194-202.

doi:10.1016/j.amjmed.2006.11.020

[8] G. V. Papatheodoridis, P. Lampertico, S. Manolakopoulos and A. Lok, "Incidence of Hepatocellular Carcinoma in Chronic Hepatitis B Patients Receiving Nucleos(t)ide Therapy: A Systematic Review," Journal of Hepatology, Vol. 53, No. 2, 2010, pp. 348-356. doi:10.1016/j.jhep.2010.02.035

[9] G. L. Davis, M. J. Alter, H. El-Serag, T. Poynard and L. W. Jennings, “Aging of Hepatitis C Virus (HCV)-Infected persons in the United States: A Multiple Cohort Model of HCV Prevalence and Disease Progression,” Gastroenterology, Vol. 138, No. 2, 2010, pp. 513-521. doi:10.1053/j.gastro.2009.09.067

[10] E. E. Calle, C. Rodriguez, K. Walker-Thurmond and M. J. Thun, "Overweight, Obesity, and Mortality from Cancer in a Prospectively Studied Cohort of US Adults," New England Journal of Medicine, Vol. 348, No. 17, 2003, pp. 1625-1638. doi:10.1056/NEJMoa021423

[11] T. Ohki, R. Tateishi, T. Sato, J. Imamura, T. Goto, N. Yamashiki, H. Yoshida, F. Kato, S. Shiina, H. Yoshida, T.
Kawabe and M. Omata, “Obesity Is an Independent Risk Factor for Hepatocellular Carcinoma Development in Chronic Hepatitis C Patients,” Clinical Gastroenterology and Hepatology, Vol. 6, No. 4, 2008, pp. 459-464. doi:10.1016/j.cgh.2008.02.012

[12] B. Goodgame, N. J. Shaheen, J. Galanko and H. B. ElSerag, "The Risk of End Stage Liver Disease and Hepatocellular Carcinoma among Persons Infected with Hepatitis C Virus: Publication Bias?” American Journal of Gastroenterology, Vol. 98, No. 11, 2003, pp. 2535-2542. doi:10.1111/j.1572-0241.2003.07678.x

[13] H. B. El-Serag, "Epidemiology of Viral Hepatitis and Hepatocellular Carcinoma,” Gastroenterology, Vol. 142, No. 5, 2012, pp. 1264-1273. doi:10.1053/j.gastro.2011.12.061

[14] A. Forner, J. M. Llovet and J. Bruix, "Hepatocellular Carcinoma,” Lancet, Vol. 379, No. 9822, 2012, pp. 12451255. doi:10.1016/S0140-6736(11)61347-0

[15] G. Fattovich, T. Stroffolini, I. Zagni and F. Donato, "Hepatocellular Carcinoma in Cirrhosis: Incidence and Risk Factors,” Gastroenterology, Vol. 127, No. 5, 2004, pp. S35-S50. doi:10.1053/j.gastro.2004.09.014

[16] F. Donato, A. Tagger, U. Gelatti, G. Parrinello, P. Boffetta, A. Albertini, A. Decarli, P. Trevisi, M. L. Ribero, C. Martelli, S. Porru and G. Nardi, “Alcohol and Hepatocellular Carcinoma: The Effect of Lifetime Intake and Hepatitis Virus Infections in Men and Women,” American Journal of Epidemiology, Vol. 155, No. 4, 2002, pp. 323-331. doi:10.1093/aje/155.4.323

[17] Expert Panel on Detection, Evaluation, and Treatment of High Blood Cholesterol in Adults, "Executive Summary of the Third Report of the National Cholesterol Education Program (NCEP) Expert Panel on Detection, Evaluation, and Treatment of High Blood Cholesterol in Adults (Adult Treatment Panel III)," Journal of the American Medical Association, Vol. 285, No. 19, 2001, pp. 24862497. doi:10.1001/jama.285.19.2486

[18] T. M. Welzel, B. I. Graubard, S. Zeuzem, H. B. El-Serag, J. A. Davila and K. A. McGlynn, "Metabolic Syndrome Increases the Risk of Primary Liver Cancer in the United States: A Study in the SEER-Medicare Database,” Hepatology, Vol. 54, No. 2, 2011, pp. 463-471. doi:10.1002/hep.24397

[19] H. B. El-Serag, T. Tran and J. E. Everhart, "Diabetes Increases the Risk of Chronic Liver Disease and Hepatocellular Carcinoma,” Gastroenterology, Vol. 126, No. 2, 2004, pp. 460-468. doi:10.1053/j.gastro.2003.10.065

[20] H. B. El-Serag, H. Hampel and F. Javadi, "The Association between Diabetes and Hepatocellular Carcinoma: A Systematic Review of Epidemiologic Evidence,” Clinical Gastroenterology and Hepatology, Vol. 4, No. 3, 2006, pp. 369-380. doi:10.1016/j.cgh.2005.12.007

[21] M. S. Ascha, I. A. Hanouneh, R. Lopez, T. A. Tamimi, A. F. Feldstein and N. N. Zein, "The Incidence and Risk Factors of Hepatocellular Carcinoma in Patients with Nonalcoholic Steatohepatitis,” Hepatology, Vol. 51, No. 6, 2010, pp. 1972-1978. doi:10.1002/hep.23527

[22] K. Yasui, E. Hashimoto, Y. Komorizono, K. Koike, S. Arii, Y. Imai, T. Shiima, Y. Kanbara, T. Saibara, T. Mori, S. Kawata, H. Uto, S. Takami, S. Sumida, T. Takamura, 
M. Kawanaka, T. Okanoue, Japan NASH Study Group, Ministry of Health Labour and Welfare of Japan, "Characteristics of Patients with Nonalcoholic Steatohepatitis Who Develop Hepatocellular Carcinoma," Clinical of Gastroenterology and Hepatology, Vol. 9, No. 5, 2011, pp. 428-433. doi:10.1016/j.cgh.2011.01.023

[23] J. Bruix and M. Sherman, "Management of Hepatocellular Carcinoma: An Update," 2011.

http://www.aasld.org/practiceguidelines/Documents/HCC Update2010.pdf

[24] A. Forner, M. Reig and J. Bruix, “Alpha-Fetoprotein for Hepatocellular Carcinoma Diagnosis: The Demise of a Brilliant Star,” Gastroenterology, Vol. 137, No. 1, 2009, pp. 26-29. doi:10.1053/j.gastro.2009.05.014

[25] J. M. Llovet, "Updated Treatment Approach to Hepatocellular Carcinoma,” Journal of Gastroenterology, Vol. 40, No. 3, 2005, pp. 225-235. doi:10.1007/s00535-005-1566-3

[26] J. A. Marrero and S. Pelletier, "Hepatocellular Carcinoma," Clinical Liver Disease, Vol. 10, No. 2, 2006, pp. 339-351.

[27] J. Bruix, M. Sherman, J. M. Llovet, M. Beaugrand, R. Leoncioni, A. K. Burroughs, E. Christensen, L. Pagliaro, M. Colombo, J. Rodes and EASL Panel of Experts on $\mathrm{H}$ Clinical Liver Disease, "Clinical Management of Hepatocellular Carcinoma. Conclusions of the Barcelona-2000 EASL Conference. European Association for the Study of the Liver,” Journal of Hepatology, Vol. 35, No. 3, 2001, pp. 421-430. doi:10.1016/S0168-8278(01)00130-1

[28] A. Forner, M. E. Reig, C. R. de Lope and J. Bruix, “Current Strategy for Staging and Treatment: The BCLC Update and Future Prospects,” Seminars of Liver Disease, Vol. 30, No. 1, 2010, pp. 61-74. doi:10.1055/s-0030-1247133

[29] V. Mazzaferro, E. Regalia, R. Dogi, S. Andreola, A. Pulvirenti, F. Bozzetti, F. Montalto, M. Ammantuna, A. Morabito and L. Gennari, "Liver Transplantation for the Treatment of Small Hepatocellular Carcinomas in Patients with Cirrhosis," New England Journal of Medicine, Vol. 334, 1996, pp. 693-369. doi:10.1056/NEJM199603143341104

[30] Y. K. Cho, J. K. Kim, M. Y. Kim, H. Rhim and J. K. Han, "Systematic Review of Randomized Trials for Hepatocellular Carcinoma Treated with Percutaneous Ablation Therapies," Hepatology, Vol. 49, No. 2, 2009, pp. 453-459. doi:10.1002/hep.22648

[31] M. S. Chen, J. Q. Li, Y. Zheng, R. P. Guo, H. H. Liang, Y. Q. Zhang, X. J. Lin and W. Y. Lau, "A Prospective Randomized Trial Comparing Per-Cutaneous Local Ablative Therapy and Partial Hepatectomy for Small Hepatocellular Carcinoma,” Annals of Surgery, Vol. 243, No. 3, 2006, pp. 321-328. doi:10.1097/01.sla.0000201480.65519.b8

[32] T. Livraghi, F. Meloni, M. Di Stasi, E. Rolle, L. Solbiati, C. Tinelli and S. Rossi, "Sustained Complete Response and Complications Rates after Radiofrequency Ablation of Very Early Hepatocellular Carcinoma in Cirrhosis: Is Resection Still the Treatment of Choice?” Hepatology, Vol. 47, No. 1, 2008, pp. 82-89. doi:10.1002/hep.21933

[33] R. N. H. Pugh, I. M. Murray-Lyon, J. L. Dawson, M. C.
Pietroni and R. Williams, "Transection of the Oesophagus for Bleeding Oesophagealvarices,” British Journal of Surgery, Vol. 60, 1973, pp. 648-652. doi:10.1002/bjs.1800600817

[34] J. B. Sorensen, M. Klee, T. Palshof and H. H. Hansen, "Performance Status Assessment in Cancer Patients. An Inter-Observer Variability Study,” British Journal of Cancer, Vol. 67, No. 4, 1993, pp. 773-775.

[35] F. J. Carrilho, L. Kikuchi, F. Branco, C. S. Goncalves and A. A. Mattos, "Clinical and Epidemiological Aspects of Hepatocellular Carcinoma in Brazil,” Clinics (Sao Paulo), Vol. 65, No. 12, 2010, pp. 1285-1290. doi:10.1590/S1807-59322010001200010

[36] R. Alves, M. Harriz, H. Vanini, D. Alves, S. Soares, T. Montalveme, D. Vanni, L. Capellano, G. Oliveira, K. Duarte, J. Ribeiro, D. Terrabuio, M. Viana, R. Moutinho, E. Taddeu, B. Guz and P. Poletti, "Carcinoma Hepatocelular: Aspectos Epidemiológicos em 210 Casos,” Revista AMRIGS, Vol. 53, No. S3, 2009, p. S43.

[37] A. S. P. Ferreira, A. J. Dominici, R. M. S. Garcia, M. E. C. Cordeiro, T. L. R. Pinho, R. S. Werniz, E. C. Santos, G. F. R. C. Santos, B. N. Tanaka, C. S. F. Carvalho and K. F. C. S. Leal, "Características Clínico-Epidemiológicas de Pacientes com Hepatocarcionoma em Serviço de Referência do Estado do Maranhão,” Revista AMRIGS, Vol. 53, No. S3, 2009, p. S79.

[38] A. S. Gonçalves, F. E. Pereira and L. C. Gayotto, "Hepatocellular Carcinoma in Brazil: Report of a National Survey (Florianopolis, SC, 1995)," Revista do Instituto de Medicina Tropical de São Paulo, Vol. 39, No. 3, 1997, pp. 165-170. doi:10.1590/S0036-46651997000300008

[39] E. Fassio, S. Díaz, C. Santa, M. E. Reig, Y. Martínez Artola and A. A. de Mattos, "Etiology of Hepatocellular Carcinoma in Latin America: A Prospective, Multicenter, International Study,” Annals of Hepatology, Vol. 9, No. 1, 2010, pp. 63-69.

[40] M. Varela, M. Reig, M. de la Mata, A. Matilla, J. Bustamante, S. Pascual, J. Turnes, C. Aracil, A. Del Val, J. M. Pascasio, M. Rodríguez and J. Bruix, "Treatment Approach of Hepatocellular Carcinoma in Spain. Analysis of 705 Patients from 62 Centers,” Medicina Clinica (Barcelona), Vol. 134, No. 13, 2010, pp. 569-576.

[41] European Association for the Study of the Liver; European Organization for Research and Treatment of Cancer, "EASL-EORTC Clinical Practice Guidelines: Management of Hepatocellular Carcinoma,” Journal of Hepatology, Vol. 56, No. 4, 2012, pp. 908-943.

[42] R. F. Silva, P. S. Fucuta, J. Vieira, A. Volpatto, M. F. Rocha and E. Cartapatti, "Carcinoma Hepatocelular no Oeste de São Paulo: Registros de um Hospital Escola," Gastroenterologia Endoscopia Digestiva, Vol. 20, 2001, p. PO249.

[43] H. B. El-Serag, "Hepatocellular Carcinoma," New England Journal of Medicine, Vol. 365, No. 12, 2011, pp. 1118-1112. doi:10.1056/NEJMra1001683

[44] M. Sherman, "Hepatocellular Carcinoma: Epidemiology, Surveillance, and Diagnosis,” Seminars Liver Disease, Vol. 30, No. 1, 2010, pp. 3-16. doi:10.1055/s-0030-1247128 
[45] A. M. Di Bisceglie, A. C. Lyra, M. Schwartz, R. K. Reddy, P. Martin, G. Gores, A. S. Lok, K. B. Hussain, R. Gish, D. H. Van Thiel, Z. Younossi, M. Tong, T. Hassanein, L. Balart, J. Fleckenstein, S. Flamm, A. Blei, A. S. Befeler and Liver Cancer Network, "Hepatitis C-Related Hepatocellular Carcinoma in the United States: Influence of Ethnic Status," American Journal of Gastroenterology, Vol. 98, No. 9, 2003, pp. 2060-2063.

[46] F. X. Bosch, J. Ribes, M. Diaz and R. Cleries, "Primary Liver Cancer: Worldwide Incidence and Trends,” Gastroenterology, Vol. 127, No. 5, 2004, pp. S5-S16. doi:10.1053/j.gastro.2004.09.011

[47] R. Raphe, H. C. C. Felício, M. F. Rocha, W. J. Duca, P. C. Arroyo Jr., D. D’Santi Neto, R. C. da Silva and R. F. da Silva, "Histopathologic Characteristics of Incidental Hepatocellular Carcinoma after Liver Transplantation,” Transplantation Procedings, Vol. 42, No. 2, 2010, pp. 505-506. doi:10.1016/j.transproceed.2010.01.034

[48] F. Trevisani, P. E. D’Intino, A. M. Morselli-Labate, G. Mazzella, E. Accogli, P. Caraceni, M. Domenicali, S. D.
Notariis, E. Roda and M. Bernardi, “Serum Alpha-Fetoprotein for Diagnosis of Hepatocellular Carcinoma in $\mathrm{Pa}$ tients with Chronic Liver Disease: Influence of $\mathrm{HBsAg}$ and Anti-HCV Status," Journal of Hepatology, Vol. 34, No. 4, 2001, pp. 570-575.

[49] J. A. Marrero, Z. Feng, Y. Wang, M. H. Nguyen, A. S. L. R. Roberts, K. R. Reddy, D. Harnois, J. M. Llovet, D. Normolle, J. Dalhgren, D. Chia, A. S. Lok, P. D. Wagner, S. Srivastava and M. Schwartz, "Alpha-Fetoprotein, DesGamma Carboxyprothrombin, and Lectin-Bound AlphaFetoprotein in Early Hepatocellular Carcinoma," Gastroenterology, Vol. 137, No. 1, 2007, pp. 110-118.

[50] A. S. Lok, R. K. Sterling, M. E. Everhart, E. C. Wright, J. C. Hoefs, A. M. Di Bisceglie, T. R. Morgan, H. Y. Kim, W. M. Lee, H. L. Bonkovsky, J. L. Dienstag and HALTC Trial Group, "Des-Gamma-Carboxyprothrombin and Alpha-Fetoprotein as Biomarkers for the Early Detection of Hepatocellular Carcinoma,” Gastroenterology, Vol. 138, No. 2, 2010, pp. 493-502. doi:10.1053/j.gastro.2009.10.031 